\title{
Reward anticipation in schizophrenia: \\ a coordinate-based meta-analysis
}

Arnaud Leroy ${ }^{a, b^{*}}$, Ali Amad ${ }^{a, b, c}$, Fabien D'Hondt ${ }^{a, b}$, Delphine Pins ${ }^{a, b, c}$,

Nematollah Jaafari ${ }^{\mathrm{c}, \mathrm{d}, \mathrm{e}}$, Pierre Thomas ${ }^{\mathrm{a}, \mathrm{b}, \mathrm{c}}$, Renaud Jardri ${ }^{\mathrm{a}, \mathrm{b}, \mathrm{c}}$

a. Univ. Lille, INSERM U1172, CHU Lille, Centre Lille Neuroscience \& Cognition, F-59000 Lille, France

b. CHU Lille, Hôpital Fontan, plateforme CURE, F-59000 Lille, France.

c. Groupement De Recherche en Psychiatrie CNRS-3557, France.

d. Unité de Recherche Clinique Intersectorielle en Psychiatrie Pierre Deniker, Centre Hospitalier Henri Laborit, 86021 Poitiers, France.

e. Univ. Poitiers \& CHU Poitiers, INSERM U-1084, Laboratoire Expérimental et Clinique en Neurosciences, 86021

Poitiers, France.

Words count: $1823+44$ references

Display items: 1 Table + 1 Figure / 2 supplementary Table +1 supplementary Figure

\section{CONTACT INFORMATION :}

Mail to*: arnaud.leroy@chru-lille.fr

Unité CURE (Centre Universitaire de Recherche et d'Exploration),

Hôpital Fontan, CHRU de Lille, rue André Verhaeghe, 59037 Lille cedex, France

Tel.: +33 320444460

fax.: +33 320444935

CONFLICT OF INTEREST: All authors declare that they have no conflicts of interest.

ROLE OF THE FUNDING SOURCE: none.

DATA AVAILABILITY: the SDM map from this study will be made available on the NeuroVault repository (https://identifiers.org/neurovault.collection:6255) 


\section{AUTHOR CONTRIBUTION:}

AL \& RJ designed the study, collected the data and made the analyses. All the authors participated in the interpretation of results, the manuscript redaction and approved its final version. 
Reward processing impairments have been linked with positive and negative symptoms of schizophrenia. Here, we performed a coordinate-based meta-analysis that combined eleven BOLD-fMRI studies comparing reward anticipation signals between schizophrenia patients and healthy controls. We observed a reduced difference in activation in schizophrenia patients within a frontal-striatal network. Meta-regressions revealed that this functional signature was linked to the severity of psychotic symptoms and persisted even after controlling for the dose of antipsychotic medications.

Key words: reward, salience, schizophrenia, antipsychotics, fMRI, meta-analysis. 


\section{INTRODUCTION}

Motivation is considered to be one of the major aspects of salience in humans (WintonBrown et al., 2014). Furthermore, motivational impairments are considered to be cardinal in schizophrenia and can be observed from the earliest stages of the disorder (Foussias and Remington, 2010; Schlosser et al., 2014). These impairments are related to deficits in anticipating future rewards (Juckel et al., 2006; Simon et al., 2010) and were shown to be associated with specific clinical features of schizophrenia. On the one hand, reward anticipation seems to be involved in the genesis of positive symptoms, i.e., hallucinations and delusions (Kapur, 2003; Murray et al., 2008), while suppressed reward processing could contribute to the reinforcement of negative symptoms, such as anhedonia (Barch and Dowd, 2010; Gold et al., 2008).

Dopamine plays a central role in the pathophysiology of schizophrenia (Howes et al., 2015), and it has also been implicated in reward signaling since dopamine neurons exhibit phasic firing during reward tasks in animals (Schultz, 2001). For several decades, D2 antagonists have been used as the reference pharmacological treatment for schizophrenia. However, their exact role in reward processing in this disorder, especially in reward anticipation, is still subject to debate (Juckel, 2016; Nielsen et al., 2018, 2012; Schlagenhauf et al., 2014).

Recent meta-analyses have addressed the question of the neural bases of reward signalling in schizophrenia and revealed activation changes in the ventral striatum (Chase et al., 2018; Radua et al., 2015). Despite the great interest these studies attract, some questions remain unanswered: (a) the inclusion of a significant number of region-of-interest (ROI) studies has exposed these meta-analyses to a bias towards the striatum. In this context, it remains difficult to fully exclude the possibility that some parts of the network involved in reward may have been missed; (b) the impact of symptom severity or medication on the resulting maps has not been directly explored.

To further these findings, we conducted a new coordinate-based meta-analysis of functional Magnetic Resonance Imaging (fMRI) studies comparing appetitive anticipation signals between patients with schizophrenia and healthy controls. Because salience and 
reward are heterogeneous concepts, we chose to focus only on anticipation rather than on more learning-dependent signals (such as reward outcome or prediction error). The aim of this work was twofold: (i) determining the whole-brain bases of reward anticipation in schizophrenia; and (ii) clarifying the impact of potential moderators on the main findings (i.e. severity, antipsychotics dosage).

\section{METHODS}

\section{Literature Selection, Data collection and preparation}

We conducted systematic MEDLINE searches until September 2018 to identify taskbased functional brain imaging studies on reward in schizophrenia. We used the following algorithm: ("schizophren* OR psychosis" "fMRI OR PET" "salienc* OR reward), complemented by the "related articles" function of the PubMed database and the reference list of studies found. To avoid bias towards the striatum, we only considered primary-data articles reporting whole-brain analyses or more than three ROls. Among the 367 initial hits, eleven met our inclusion/exclusion criteria (see the PRISMA Flowchart in Figure S1). Selected activation studies are listed in Table 1 (Chung and Barch, 2016; da Silva Alves et al., 2013; Gradin et al., 2011; Koch et al., 2010; Potvin et al., 2016; Reckless et al., 2015; Richter et al., 2015; Schlagenhauf et al., 2009; Smieskova et al., 2015; Subramaniam et al., 2015; Walter et al., 2009). They referred to a Monetary Incentive Delay (MID) or similar task and reported the following fMRI contrasts: [reward anticipation vs. neutral cue] in [controls vs. schizophrenia patients]. Both controls > schizophrenia and schizophrenia > controls contrasts are reported, because the SDM meta-analysis software accounts for peaks' effect size and sign to counteract positive and negative differences. Stereotaxic coordinates of the 44 foci of interest for these contrasts were extracted and tagged by study and sample size. We considered only foci reported as significant at an uncorrected $p$-value $<0.001$ or $p$-value $<0.05$ corrected for multiple comparisons in the source studies. 


\section{Meta-Analysis Procedure}

Data were analyzed using the SDM (seed-based d mapping) algorithm (Radua et al., 2012; Radua and Mataix-Cols, 2009). Effect sizes were calculated using (i) t-scores in the voxels containing a peak and (ii) a Gaussian kernel applied to the surrounding voxels (Radua et al., 2014). Estimated statistical maps were then included in a random effects meta-analytic model that weighted the contribution of each study according to its sample size and intra/interstudy heterogeneity. The statistical significance of the resulting SDM Z-maps was estimated through 50 permutation tests. Following standard criteria, intergroup comparisons were limited to (i) $\mathrm{p}<0.005$ (Rauch et al., 2002); (ii) an SDM Z-score $>1$; and (iii) a cluster extent $>10$ voxels (Radua et al., 2012; Radua and Mataix- Cols, 2009). A jackknife sensitivity analysis was conducted to assess the robustness of the findings by iteratively repeating the analysis and by excluding one dataset at a time, while a potential publication bias was assessed using Egger's tests and funnel plots. We verified that when results were changed in a particular dataset combination in the jackknife analysis, the discarded study did not drive the results using a visual inspection of funnel plots. We also verified that Egger's test was not significant $(p>0.05)$.

Finally, we performed voxelwise meta-regressions to assess the influence of potential moderators on the Group x Reward effect. For symptom severity, we used the average Positive and Negative Syndrome Scale (PANSS) total and subscores from each study. When necessary, a conversion from other scales to the PANSS was performed (van Erp et al., 2014). We also investigated the impact of the medication dosage converted to chlorpromazine equivalents (Gardner et al., 2010) on group differences. The moderating role of antipsychotics was then controlled for the mean symptom severity. Meta-regressions were limited to $p<0.0005$ (Thorsen et al., 2018), while findings in regions other than those detected in the main analyses were discarded (Radua and Mataix-Cols, 2009). 


\section{RESULTS}

\section{Meta-analytical estimates of brain responses during reward anticipation}

We collected data for 488 subjects (254 schizophrenia patients and 234 controls) and 44 foci (Table 1). When comparing controls with patients for the [reward anticipation vs. neutral cue] contrast, we demonstrated an increased difference in activation, i.e., [reward anticipation > neutral cue] in [controls > schizophrenia patients], within a network involving the left striatum, the right median cingulate/paracingulate gyri, the left thalamus, the left postcentral gyrus, the left middle frontal gyrus, the cerebellum and the superior temporal gyrus.

After applying a jackknife analysis (testing for heterogeneity between clusters), Egger's tests and funnel plots (testing for the heterogeneity between studies), only the left striatum and the right median cingulate/paracingulate gyri remained reliable regions for consideration in the [controls>schizophrenia patients] contrast (Figure 1A). No significant difference was demonstrated for the [schizophrenia patients>controls] contrast (Table S1). 
Table 1: Characteristics of the activation studies included in the meta-analysis. Mixed studies recruited patients corresponding to (a) first-episode psychosis and (b) chronic schizophrenia categories.

\begin{tabular}{|l|c|l|c|c|l|}
\hline Study & Number of patients & Type of patients & Number of controls & Number of foci & Design \\
\hline Alves et al. & 10 & First episode & 12 & 2 & Monetary incentive Delay Task \\
Gradin et al. & 15 & Chronic & 20 & 5 & Instrumental reward learning task \\
Koch et al. & 44 & Chronic & 44 & 21 & Monetary incentive Delay Task \\
Walter et al. & 16 & Chronic & 16 & 1 & Monetary incentive Delay Task \\
Schlagenhauf et al. & 15 & First episode and chronic & 15 & 2 & Monetary incentive Delay Task \\
Smieskova et al. & 29 & First episode & 19 & 3 & Salience Attribution Task \\
Subramaniam et al. & 37 & Chronic & 20 & 1 & Monetary incentive Delay Task \\
Richter et al. & 16 & Chronic & 16 & 5 & Desire-reason-dilemma paradigm \\
Chung et al. & 36 & Chronic & 27 & 1 & Variant of a response conflict task \\
Potvin et al. & 18 & Chronic & 24 & 2 & Cue associated with smoking \\
Reckless et al & 18 & Chronic & 21 & 1 & Rewarded perceptual decision-making task \\
\hline
\end{tabular}



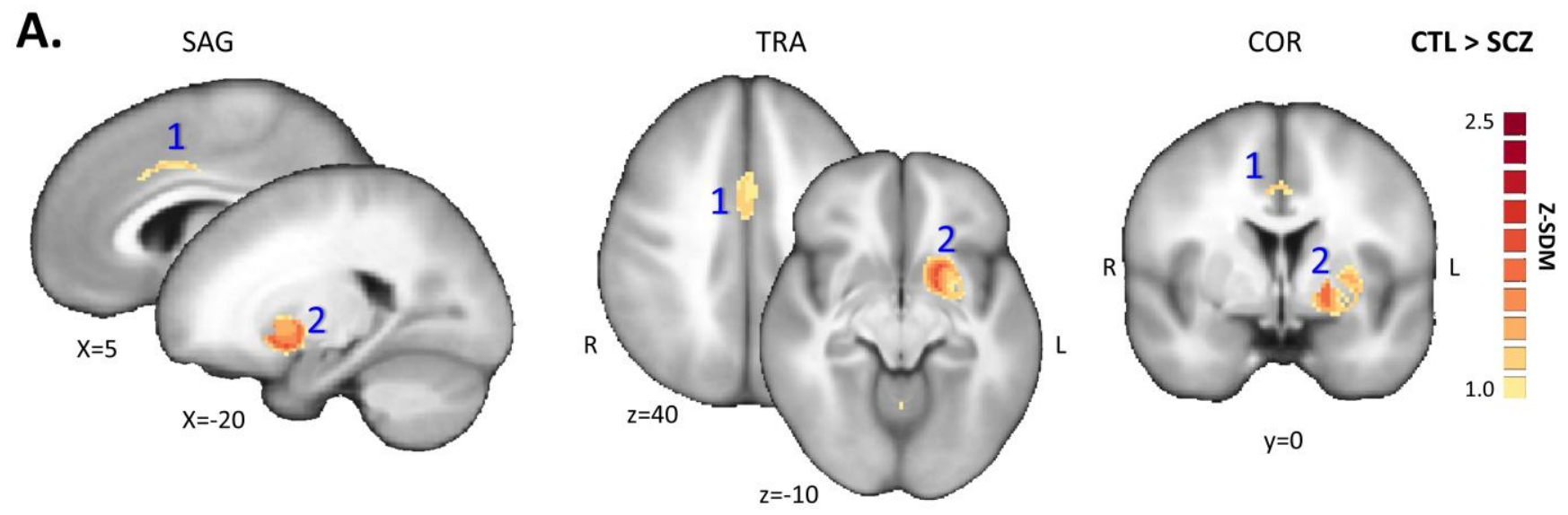

B.

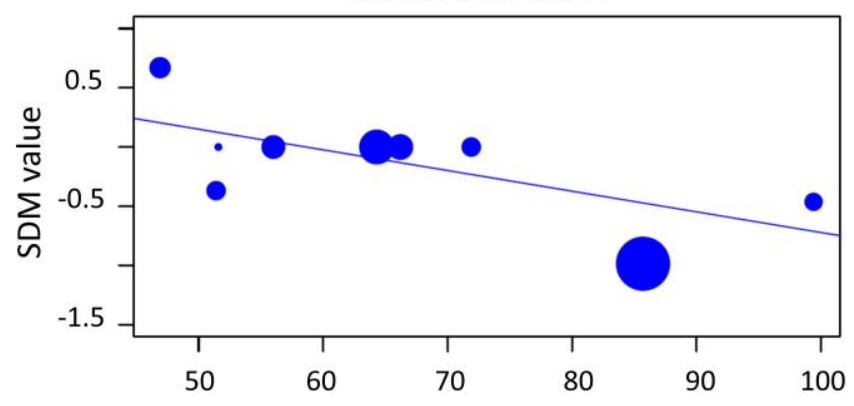

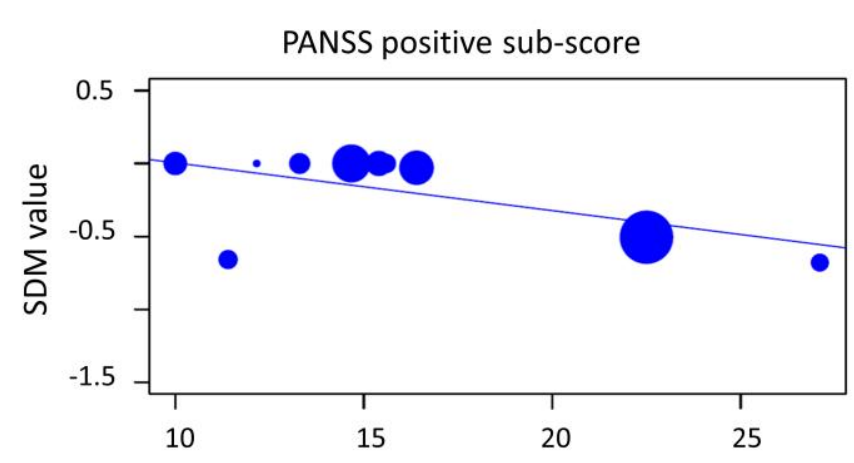

Figure 1: Coordinate-based meta-analytic findings for reward anticipation in schizophrenia.

1A. Inter-group effect size on signed differential maps during reward anticipation in schizophrenia. The right median cingulate/paracingulate gyri (1) and left striatum (2) were significant for the contrast [controls > schizophrenia patients (SCZ)] and survived (a) jackknife analysis, (b) Egger's tests and (c) funnel plots analyses.

1B. Meta-regression analysis testing for an association between symptom severity in the left striatum. Larger circles indicate studies with a larger sample size. The meta-regression SDM slope after controlling for the dosage of antipsychotics is presented as a straight line for average PANSS global scores (left panel) and PANSS positive sub-scores (right panel). Note that the meta-regression SDM value is derived from the proportion of studies that reported BOLD change near the voxel, so it is expected that the values of some of the studies are at 0 or near +1 (instead of being close to the line). "PANSS": Positive and Negative Syndrome Scale; "SDM": signed d mapping. 


\section{Potential effect of symptoms severity and medication}

Voxel-wise meta-regressions revealed that the left striatum was more affected in the contrast [reward anticipation > neutral cue] in [controls > schizophrenia patients] in severe schizophrenia patients (i.e. with higher total PANSS scores), independent of medication (Figure 1B). More precisely, less striatal activation was demonstrated in patients exhibiting more severe psychotic symptoms (PANSS positive sub-scores), even after controlling for the dosage of antipsychotics (Figure 1B). 


\section{DISCUSSION}

In the present paper, we produced robust whole-brain meta-analytic maps associated with reward anticipation in schizophrenia. We showed that during reward anticipation, schizophrenia patients exhibit a reduced difference in activation in two key nodes of the putative salience network, the left striatum and the cingulate/paracingulate gyri. These findings support the idea that reward anticipation extends beyond the ventral striatum (VS) (Radua et al., 2015). Furthermore, our results are fully compatible with recent exploration in the healthy brain underscoring the role played by these nodes in reward anticipation (Wilson et al., 2018). Critically, we showed that within this salience network, VS hypoactivation was more pronounced in schizophrenia patients exhibiting more severe positive symptoms. These results remained significant even after controlling for the effect of antipsychotic dosage, suggesting that they are not driven by medication (Juckel, 2016).

Despite some methodological differences, our findings nicely complement three previous meta-analyses addressing similar questions: one taking a strict region-of-interest approach (Radua et al., 2015); another using a transdiagnosis approach, beyond schizophrenia (Zhang et al., 2016); and a last one that explored wider and more heterogeneous rewardrelated brain activation (Chase et al., 2018). We made the choice to focus only on anticipation of reward studies to favor a homogeneous selection of activation studies. Even if this remains a point of debate, some studies have suggested that anticipation of reward and prediction error may only partially share their neural bases. First, at the behavioral level (as in MID tasks), processes related to anticipation, outcome and prediction error can be separated (Knutson et al., 2000). Furthermore, electrophysiological studies have reported that reward signals of dopamine neurons were influenced by reward predictability (Hollerman and Schultz, 1998). Finally, recent fMRI studies (Cao et al., 2019) have shown that different reward processing stages during the MID task were associated with distinct patterns of activation and connectivity. By performing a new prediction-error meta-analysis (based on 11 studies and using similar selection quality criteria), we were also able to provide evidence for differences with anticipation of reward, notably a nonrobust significant result in the cingulate for the [controls>schizophrenia patients] contrast (Table S2). What can initially appear as a power issue (i.e., 11 selected studies) was in fact balanced by the quality and homogeneity of the 
papers used (Müller et al., 2018). We further ensured the robustness of our findings by (i) taking into account covariates such as symptom severity and medications, (ii) applying a restrictive threshold (Thorsen et al., 2018), and (iii) conducting a sensitivity analysis. However, the small number of studies makes it impossible to examine other issues, such as whether the results differed as a function of paradigms (e.g., MID vs. other types of tasks) or stages of illness (early vs chronic).

Furthermore, emotionally salient stimuli could have been an issue in the generation of reproducible findings because of their greater dependence on the patient's history (WintonBrown et al., 2014), and we excluded studies using these kinds of stimuli. In contrast, reward stimuli, such as monetary rewards, seem more reliable (Daniel and Pollmann, 2010). The brain responses were also shown to vary between different types of salience, such as emotional salience or salience linked to novelty (Knolle et al., 2018). At this stage, it remains difficult to fully exclude the possibility that alternative procedures may have resulted in different rewardrelated functional results in the VS and, more globally, in the salience network. For instance, we did not replicate left VS hypoactivation in patients with more negative symptoms, which was a result observed in a previous striatum-focused meta-analysis (Radua et al., 2015).

Overall, we demonstrated a robust frontal-striatal signature of impaired reward anticipation in schizophrenia patients. In this study, we aimed to analyze a very homogeneous selection of studies, to reflect on paper selection from the reward literature and to perform meta-regression on symptom severity and dosage of treatment, which has not been done before. Within this functional network, VS hypoactivation was linked to the severity of psychotic symptoms, even when controlling for medication dosage. 
Table S1. Coordinate-based meta-analytic complementary results. Brain regions with significant activations during reward anticipation for the contrast [controls $>$ patients with schizophrenia] or [patients with schizophrenia > controls]. MNI: Montreal Neurological Institute; “*” means nearest grey matter.

\begin{tabular}{|c|c|c|c|c|l|c|c|}
\hline Clusters & Coordinate (MNI) & Number of voxels & $\mathbf{p}$ & SDM-Z & Label & Jacknife \\
\hline 1 & $-16,6,-4$ & 606 & 0.000045538 & -2.137 & Left striatum & $9 / 11$ \\
2 & $6,8,36$ & 110 & 0.001922309 & -1.635 & Right median cingulate/paracingulate gyri & 0.553 \\
3 & $-2,-14,6$ & 80 & 0.001346052 & -1.691 & Left thalamus & 0.268 \\
4 & $-42,-16,34$ & 35 & 0.001594365 & -1.666 & Left postcentral gyrus* & $10 / 11$ \\
5 & $-38,50,0$ & 24 & 0.002998114 & -1.56 & Left middle frontal gyrus & 0.016 \\
6 & $4,-60,-8$ & 22 & 0.003202200 & -1.548 & Cerebellum, vermic lobule, BA 18 & 0.063 \\
7 & $56,12,-12$ & 11 & 0.002559066 & -1.587 & Right temporal pole, superior temporal gyrus, BA 38 & $1 / 11$ \\
\hline
\end{tabular}

Table S2. Coordinate-based meta-analytic complementary results. Brain regions with significant activations during prediction error for the contrast [controls > patients with schizophrenia] or [patients with schizophrenia > controls]. MNI: Montreal Neurological Institute; “*” means nearest grey matter.

\begin{tabular}{|c|c|c|c|c|c|c|c|}
\hline Clusters & Coordinate (MNI) & Number of voxels & p & SDM-Z & Label & Jacknife & p Egger's test \\
\hline 1 & $0,-42,36$ & 659 & 0,000508249 & $-1,82$ & Left median cingulate/paracingulate gyri & $6 / 10$ & 0.09 \\
\hline 2 & $0,-6,-8$ & 148 & 0,000837684 & $-1,754$ & undefined & $2 / 10$ & 0.20 \\
\hline 3 & $-2,-14,6$ & 36 & 0,003093004 & $-1,556$ & Right precuneus & $7 / 10$ & 0.14 \\
\hline
\end{tabular}




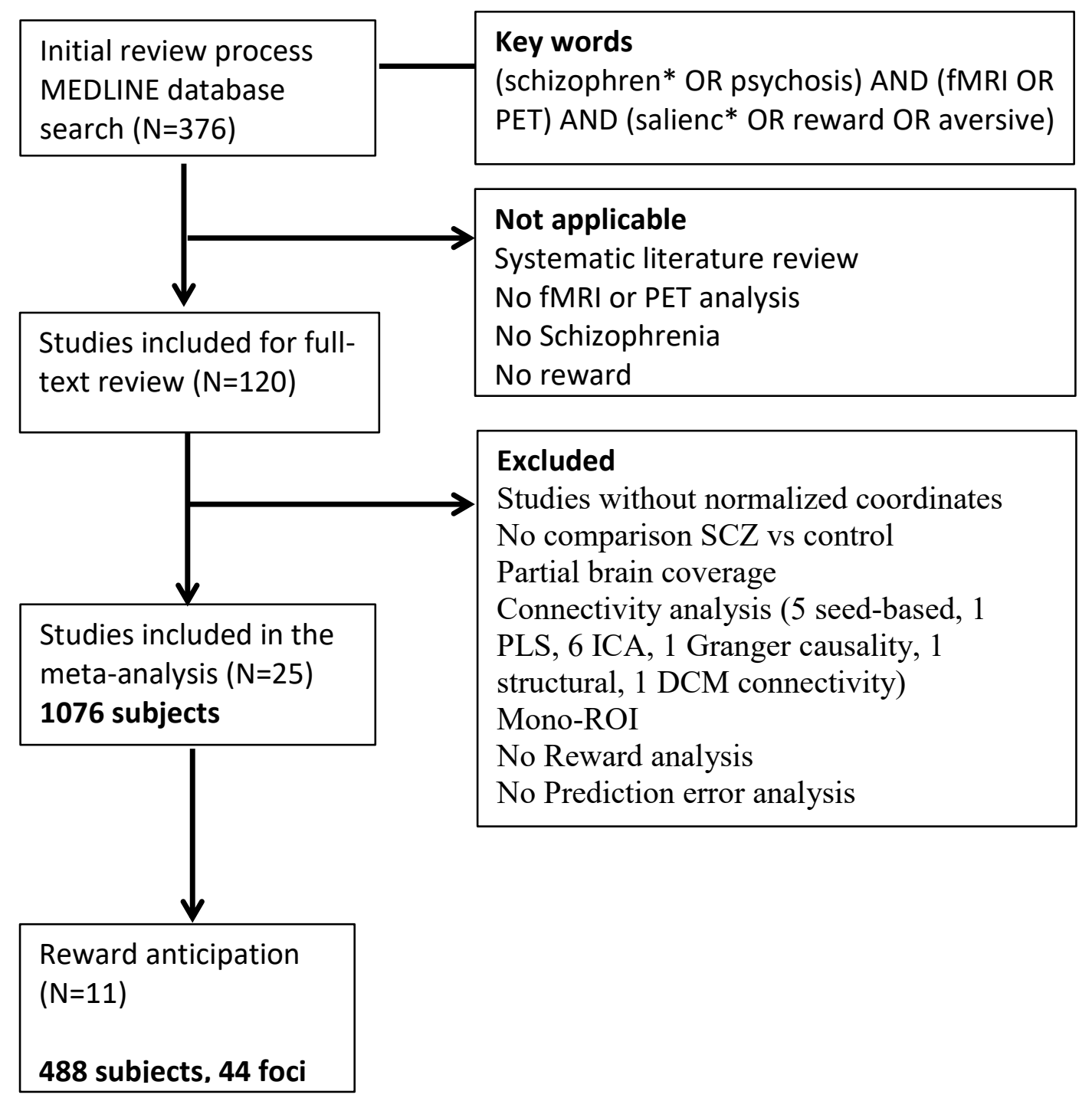

Figure S1. PRISMA Flow diagram of article selection process. 
Barch, D.M., Dowd, E.C., 2010. Goal representations and motivational drive in schizophrenia: the role of prefrontal-striatal interactions. Schizophr. Bull. 36, 919-934. https://doi.org/10.1093/schbul/sbq068

Chase, H.W., Loriemi, P., Wensing, T., Eickhoff, S.B., Nickl-Jockschat, T., 2018. Meta-analytic evidence for altered mesolimbic responses to reward in schizophrenia. Hum. Brain Mapp. 39, 2917-2928. https://doi.org/10.1002/hbm.24049

Chung, Y.S., Barch, D.M., 2016. Frontal-striatum dysfunction during reward processing: Relationships to amotivation in schizophrenia. J. Abnorm. Psychol. 125, 453-469. https://doi.org/10.1037/abn0000137

da Silva Alves, F., Bakker, G., Schmitz, N., Abeling, N., Hasler, G., van der Meer, J., Nederveen, A., de Haan, L., Linszen, D., van Amelsvoort, T., 2013. Dopaminergic modulation of the reward system in schizophrenia: a placebo-controlled dopamine depletion fMRI study. Eur. Neuropsychopharmacol. J. Eur. Coll. Neuropsychopharmacol. 23, 1577-1586. https://doi.org/10.1016/j.euroneuro.2013.06.008

Foussias, G., Remington, G., 2010. Negative symptoms in schizophrenia: avolition and Occam's razor. Schizophr. Bull. 36, 359-369. https://doi.org/10.1093/schbul/sbn094

Gold, J.M., Waltz, J.A., Prentice, K.J., Morris, S.E., Heerey, E.A., 2008. Reward processing in schizophrenia: a deficit in the representation of value. Schizophr. Bull. 34, 835-847. https://doi.org/10.1093/schbul/sbn068

Gradin, V.B., Kumar, P., Waiter, G., Ahearn, T., Stickle, C., Milders, M., Reid, I., Hall, J., Steele, J.D., 2011. Expected value and prediction error abnormalities in depression and schizophrenia. Brain J. Neurol. 134, 1751-1764. https://doi.org/10.1093/brain/awr059

Hollerman, J.R., Schultz, W., 1998. Dopamine neurons report an error in the temporal prediction of reward during learning. Nat. Neurosci. 1, 304-309. https://doi.org/10.1038/1124

Howes, O., McCutcheon, R., Stone, J., 2015. Glutamate and dopamine in schizophrenia: an update for the 21st century. J. Psychopharmacol. Oxf. Engl. 29, 97-115. https://doi.org/10.1177/0269881114563634

Juckel, G., 2016. Inhibition of the reward system by antipsychotic treatment. Dialogues Clin. Neurosci. 18, 109-114.

Juckel, G., Schlagenhauf, F., Koslowski, M., Wüstenberg, T., Villringer, A., Knutson, B., Wrase, J., Heinz, A., 2006. Dysfunction of ventral striatal reward prediction in schizophrenia. Neurolmage 29, 409-416. https://doi.org/10.1016/j.neuroimage.2005.07.051

Kapur, S., 2003. Psychosis as a state of aberrant salience: a framework linking biology, phenomenology, and pharmacology in schizophrenia. Am. J. Psychiatry 160, 13-23. https://doi.org/10.1176/appi.ajp.160.1.13

Knolle, F., Ermakova, A.O., Justicia, A., Fletcher, P.C., Bunzeck, N., Düzel, E., Murray, G.K., 2018. Brain responses to different types of salience in antipsychotic naïve first episode psychosis: An fMRI study. Transl. Psychiatry 8, 196. https://doi.org/10.1038/s41398-018-0250-3

Knutson, B., Westdorp, A., Kaiser, E., Hommer, D., 2000. FMRI visualization of brain activity during a monetary incentive delay task. Neurolmage 12, 20-27. https://doi.org/10.1006/nimg.2000.0593

Koch, K., Schachtzabel, C., Wagner, G., Schikora, J., Schultz, C., Reichenbach, J.R., Sauer, H., Schlösser, R.G.M., 2010. Altered activation in association with reward-related trial-and-error 
learning in patients with schizophrenia. Neurolmage 50, 223-232. https://doi.org/10.1016/j.neuroimage.2009.12.031

Müller, V.I., Cieslik, E.C., Laird, A.R., Fox, P.T., Radua, J., Mataix-Cols, D., Tench, C.R., Yarkoni, T., Nichols, T.E., Turkeltaub, P.E., Wager, T.D., Eickhoff, S.B., 2018. Ten simple rules for neuroimaging meta-analysis. Neurosci. Biobehav. Rev. 84, 151-161. https://doi.org/10.1016/j.neubiorev.2017.11.012

Murray, G., Corlett, P., Clark, L., Pessiglione, M., Blackwell, A., Honey, G., Jones, P., Bullmore, E., Robbins, T., Fletcher, P., 2008. Substantia nigra/ventral tegmental reward prediction error disruption in psychosis. Mol. Psychiatry 13, 239-276. https://doi.org/10.1038/sj.mp.4002058 Nielsen, M.Ø., Rostrup, E., Broberg, B.V., Wulff, S., Glenthøj, B., 2018. Negative Symptoms and Reward Disturbances in Schizophrenia Before and After Antipsychotic Monotherapy. Clin. EEG Neurosci. 49, 36-45. https://doi.org/10.1177/1550059417744120

Nielsen, M.O., Rostrup, E., Wulff, S., Bak, N., Broberg, B.V., Lublin, H., Kapur, S., Glenthoj, B., 2012. Improvement of brain reward abnormalities by antipsychotic monotherapy in schizophrenia. Arch. Gen. Psychiatry 69, 1195-1204. https://doi.org/10.1001/archgenpsychiatry.2012.847

Potvin, S., Lungu, O., Lipp, O., Lalonde, P., Zaharieva, V., Stip, E., Melun, J.-P., Mendrek, A., 2016. Increased ventro-medial prefrontal activations in schizophrenia smokers during cigarette cravings. Schizophr. Res. 173, 30-36. https://doi.org/10.1016/j.schres.2016.03.011 Radua, J., Grau, M., van den Heuvel, O.A., Thiebaut de Schotten, M., Stein, D.J., CanalesRodríguez, E.J., Catani, M., Mataix-Cols, D., 2014. Multimodal voxel-based meta-analysis of white matter abnormalities in obsessive-compulsive disorder. Neuropsychopharmacol. Off. Publ. Am. Coll. Neuropsychopharmacol. 39, 1547-1557. https://doi.org/10.1038/npp.2014.5 Radua, J., Mataix-Cols, D., 2009. Voxel-wise meta-analysis of grey matter changes in obsessivecompulsive disorder. Br. J. Psychiatry J. Ment. Sci. 195, 393-402. https://doi.org/10.1192/bjp.bp.108.055046

Radua, J., Mataix-Cols, D., Phillips, M.L., El-Hage, W., Kronhaus, D.M., Cardoner, N., Surguladze, S., 2012. A new meta-analytic method for neuroimaging studies that combines reported peak coordinates and statistical parametric maps. Eur. Psychiatry J. Assoc. Eur. Psychiatr. 27, 605-611. https://doi.org/10.1016/j.eurpsy.2011.04.001

Radua, J., Schmidt, A., Borgwardt, S., Heinz, A., Schlagenhauf, F., McGuire, P., Fusar-Poli, P., 2015. Ventral Striatal Activation During Reward Processing in Psychosis: A Neurofunctional $\begin{array}{llll}\text { Meta-Analysis. JAMA Psychiatry 12, } & \text { 1243-1251. }\end{array}$ https://doi.org/10.1001/jamapsychiatry.2015.2196

Rauch, S.L., Shin, L.M., Dougherty, D.D., Alpert, N.M., Fischman, A.J., Jenike, M.A., 2002. Predictors of fluvoxamine response in contamination-related obsessive compulsive disorder: a PET symptom provocation study. Neuropsychopharmacol. Off. Publ. Am. Coll. Neuropsychopharmacol. 27, 782-791. https://doi.org/10.1016/S0893-133X(02)00351-2

Reckless, G.E., Andreassen, O.A., Server, A., Østefjells, T., Jensen, J., 2015. Negative symptoms in schizophrenia are associated with aberrant striato-cortical connectivity in a rewarded perceptual decision-making task. Neurolmage Clin. 8, 290-297. https://doi.org/10.1016/j.nicl.2015.04.025

Richter, A., Petrovic, A., Diekhof, E.K., Trost, S., Wolter, S., Gruber, O., 2015. Hyperresponsivity and impaired prefrontal control of the mesolimbic reward system in schizophrenia. J. Psychiatr. Res. 71, 8-15. https://doi.org/10.1016/j.jpsychires.2015.09.005

Schlagenhauf, F., Huys, Q.J.M., Deserno, L., Rapp, M.A., Beck, A., Heinze, H.-J., Dolan, R., Heinz, A., 2014. Striatal dysfunction during reversal learning in unmedicated schizophrenia patients. 
Neurolmage 89, 171-180. https://doi.org/10.1016/j.neuroimage.2013.11.034

Schlagenhauf, F., Sterzer, P., Schmack, K., Ballmaier, M., Rapp, M., Wrase, J., Juckel, G., Gallinat, J., Heinz, A., 2009. Reward feedback alterations in unmedicated schizophrenia patients: relevance for delusions. Biol. Psychiatry 65, 1032-1039. https://doi.org/10.1016/j.biopsych.2008.12.016

Schlosser, D.A., Fisher, M., Gard, D., Fulford, D., Loewy, R.L., Vinogradov, S., 2014. Motivational deficits in individuals at-risk for psychosis and across the course of schizophrenia. Schizophr. Res. 158, 52-57. https://doi.org/10.1016/j.schres.2014.06.024

Schultz, W., 2001. Reward signaling by dopamine neurons. Neurosci. Rev. J. Bringing Neurobiol. Neurol. Psychiatry 7, 293-302. https://doi.org/10.1177/107385840100700406 Simon, J.J., Biller, A., Walther, S., Roesch-Ely, D., Stippich, C., Weisbrod, M., Kaiser, S., 2010. Neural correlates of reward processing in schizophrenia--relationship to apathy and depression. Schizophr. Res. 118, 154-161. https://doi.org/10.1016/j.schres.2009.11.007

Smieskova, R., Roiser, J.P., Chaddock, C.A., Schmidt, A., Harrisberger, F., Bendfeldt, K., Simon, A., Walter, A., Fusar-Poli, P., McGuire, P.K., Lang, U.E., Riecher-Rössler, A., Borgwardt, S., 2015. Modulation of motivational salience processing during the early stages of psychosis. Schizophr. Res. 166, 17-23. https://doi.org/10.1016/j.schres.2015.04.036

Subramaniam, K., Hooker, C.I., Biagianti, B., Fisher, M., Nagarajan, S., Vinogradov, S., 2015. Neural signal during immediate reward anticipation in schizophrenia: Relationship to realworld motivation and function. Neurolmage Clin. 9, 153-163. https://doi.org/10.1016/j.nicl.2015.08.001

Thorsen, A.L., Hagland, P., Radua, J., Mataix-Cols, D., Kvale, G., Hansen, B., van den Heuvel, O.A., 2018. Emotional Processing in Obsessive-Compulsive Disorder: A Systematic Review and Meta-analysis of 25 Functional Neuroimaging Studies. Biol. Psychiatry Cogn. Neurosci. Neuroimaging 3, 563-571. https://doi.org/10.1016/j.bpsc.2018.01.009

van Erp, T.G.M., Preda, A., Nguyen, D., Faziola, L., Turner, J., Bustillo, J., Belger, A., Lim, K.O., McEwen, S., Voyvodic, J., Mathalon, D.H., Ford, J., Potkin, S.G., Fbirn, null, 2014. Converting positive and negative symptom scores between PANSS and SAPS/SANS. Schizophr. Res. 152, 289-294. https://doi.org/10.1016/j.schres.2013.11.013

Walter, H., Kammerer, H., Frasch, K., Spitzer, M., Abler, B., 2009. Altered reward functions in patients on atypical antipsychotic medication in line with the revised dopamine hypothesis of schizophrenia. Psychopharmacology (Berl.) 206, 121-132. https://doi.org/10.1007/s00213009-1586-4

Wilson, R.P., Colizzi, M., Bossong, M.G., Allen, P., Kempton, M., MTAC, Bhattacharyya, S., 2018. The Neural Substrate of Reward Anticipation in Health: A Meta-Analysis of fMRI Findings in the Monetary Incentive Delay Task. Neuropsychol. Rev. https://doi.org/10.1007/s11065018-9385-5

Winton-Brown, T.T., Fusar-Poli, P., Ungless, M.A., Howes, O.D., 2014. Dopaminergic basis of salience dysregulation in psychosis. Trends Neurosci. 37, 85-94. https://doi.org/10.1016/j.tins.2013.11.003

Zhang, B., Lin, P., Shi, H., Öngür, D., Auerbach, R.P., Wang, Xiaosheng, Yao, S., Wang, Xiang, 2016. Mapping anhedonia-specific dysfunction in a transdiagnostic approach: an ALE metaanalysis. Brain Imaging Behav. 10, 920-939. https://doi.org/10.1007/s11682-015-9457-6 Barch, D.M., Dowd, E.C., 2010. Goal representations and motivational drive in schizophrenia: the role of prefrontal-striatal interactions. Schizophr. Bull. 36, 919-934. https://doi.org/10.1093/schbul/sbq068

Chase, H.W., Loriemi, P., Wensing, T., Eickhoff, S.B., Nickl-Jockschat, T., 2018. Meta-analytic 
evidence for altered mesolimbic responses to reward in schizophrenia. Hum. Brain Mapp. 39, 2917-2928. https://doi.org/10.1002/hbm.24049

Chung, Y.S., Barch, D.M., 2016. Frontal-striatum dysfunction during reward processing: Relationships to amotivation in schizophrenia. J. Abnorm. Psychol. 125, 453-469. https://doi.org/10.1037/abn0000137

da Silva Alves, F., Bakker, G., Schmitz, N., Abeling, N., Hasler, G., van der Meer, J., Nederveen, A., de Haan, L., Linszen, D., van Amelsvoort, T., 2013. Dopaminergic modulation of the reward system in schizophrenia: a placebo-controlled dopamine depletion fMRI study. Eur. Neuropsychopharmacol. J. Eur. Coll. Neuropsychopharmacol. 23, 1577-1586. https://doi.org/10.1016/j.euroneuro.2013.06.008

Foussias, G., Remington, G., 2010. Negative symptoms in schizophrenia: avolition and Occam's razor. Schizophr. Bull. 36, 359-369. https://doi.org/10.1093/schbul/sbn094

Gold, J.M., Waltz, J.A., Prentice, K.J., Morris, S.E., Heerey, E.A., 2008. Reward processing in schizophrenia: a deficit in the representation of value. Schizophr. Bull. 34, 835-847. https://doi.org/10.1093/schbul/sbn068

Gradin, V.B., Kumar, P., Waiter, G., Ahearn, T., Stickle, C., Milders, M., Reid, I., Hall, J., Steele, J.D., 2011. Expected value and prediction error abnormalities in depression and schizophrenia. Brain J. Neurol. 134, 1751-1764. https://doi.org/10.1093/brain/awr059

Hollerman, J.R., Schultz, W., 1998. Dopamine neurons report an error in the temporal prediction of reward during learning. Nat. Neurosci. 1, 304-309. https://doi.org/10.1038/1124

Howes, O., McCutcheon, R., Stone, J., 2015. Glutamate and dopamine in schizophrenia: an update for the 21st century. J. Psychopharmacol. Oxf. Engl. 29, 97-115. https://doi.org/10.1177/0269881114563634

Juckel, G., 2016. Inhibition of the reward system by antipsychotic treatment. Dialogues Clin. Neurosci. 18, 109-114.

Juckel, G., Schlagenhauf, F., Koslowski, M., Wüstenberg, T., Villringer, A., Knutson, B., Wrase, J., Heinz, A., 2006. Dysfunction of ventral striatal reward prediction in schizophrenia. Neurolmage 29, 409-416. https://doi.org/10.1016/j.neuroimage.2005.07.051

Kapur, S., 2003. Psychosis as a state of aberrant salience: a framework linking biology, phenomenology, and pharmacology in schizophrenia. Am. J. Psychiatry 160, 13-23. https://doi.org/10.1176/appi.ajp.160.1.13

Knolle, F., Ermakova, A.O., Justicia, A., Fletcher, P.C., Bunzeck, N., Düzel, E., Murray, G.K., 2018. Brain responses to different types of salience in antipsychotic naïve first episode psychosis: An fMRI study. Transl. Psychiatry 8, 196. https://doi.org/10.1038/s41398-018-0250-3

Knutson, B., Westdorp, A., Kaiser, E., Hommer, D., 2000. FMRI visualization of brain activity during a monetary incentive delay task. Neurolmage 12, 20-27. https://doi.org/10.1006/nimg.2000.0593

Koch, K., Schachtzabel, C., Wagner, G., Schikora, J., Schultz, C., Reichenbach, J.R., Sauer, H., Schlösser, R.G.M., 2010. Altered activation in association with reward-related trial-and-error learning in patients with schizophrenia. Neurolmage 50, 223-232. https://doi.org/10.1016/j.neuroimage.2009.12.031

Müller, V.I., Cieslik, E.C., Laird, A.R., Fox, P.T., Radua, J., Mataix-Cols, D., Tench, C.R., Yarkoni, T., Nichols, T.E., Turkeltaub, P.E., Wager, T.D., Eickhoff, S.B., 2018. Ten simple rules for neuroimaging meta-analysis. Neurosci. Biobehav. Rev. 84, 151-161. https://doi.org/10.1016/j.neubiorev.2017.11.012

Murray, G., Corlett, P., Clark, L., Pessiglione, M., Blackwell, A., Honey, G., Jones, P., Bullmore, 
E., Robbins, T., Fletcher, P., 2008. Substantia nigra/ventral tegmental reward prediction error disruption in psychosis. Mol. Psychiatry 13, 239-276. https://doi.org/10.1038/sj.mp.4002058 Nielsen, M.Ø., Rostrup, E., Broberg, B.V., Wulff, S., Glenthøj, B., 2018. Negative Symptoms and Reward Disturbances in Schizophrenia Before and After Antipsychotic Monotherapy. Clin. EEG Neurosci. 49, 36-45. https://doi.org/10.1177/1550059417744120

Nielsen, M.O., Rostrup, E., Wulff, S., Bak, N., Broberg, B.V., Lublin, H., Kapur, S., Glenthoj, B., 2012. Improvement of brain reward abnormalities by antipsychotic monotherapy in schizophrenia. Arch. Gen. Psychiatry 69, 1195-1204. https://doi.org/10.1001/archgenpsychiatry.2012.847

Potvin, S., Lungu, O., Lipp, O., Lalonde, P., Zaharieva, V., Stip, E., Melun, J.-P., Mendrek, A., 2016. Increased ventro-medial prefrontal activations in schizophrenia smokers during cigarette cravings. Schizophr. Res. 173, 30-36. https://doi.org/10.1016/j.schres.2016.03.011 Radua, J., Grau, M., van den Heuvel, O.A., Thiebaut de Schotten, M., Stein, D.J., CanalesRodríguez, E.J., Catani, M., Mataix-Cols, D., 2014. Multimodal voxel-based meta-analysis of white matter abnormalities in obsessive-compulsive disorder. Neuropsychopharmacol. Off. Publ. Am. Coll. Neuropsychopharmacol. 39, 1547-1557. https://doi.org/10.1038/npp.2014.5 Radua, J., Mataix-Cols, D., 2009. Voxel-wise meta-analysis of grey matter changes in obsessivecompulsive disorder. Br. J. Psychiatry J. Ment. Sci. 195, 393-402. https://doi.org/10.1192/bjp.bp.108.055046

Radua, J., Mataix-Cols, D., Phillips, M.L., El-Hage, W., Kronhaus, D.M., Cardoner, N., Surguladze, S., 2012. A new meta-analytic method for neuroimaging studies that combines reported peak coordinates and statistical parametric maps. Eur. Psychiatry J. Assoc. Eur. Psychiatr. 27, 605-611. https://doi.org/10.1016/j.eurpsy.2011.04.001

Radua, J., Schmidt, A., Borgwardt, S., Heinz, A., Schlagenhauf, F., McGuire, P., Fusar-Poli, P., 2015. Ventral Striatal Activation During Reward Processing in Psychosis: A Neurofunctional $\begin{array}{llll}\text { Meta-Analysis. JAMA } & \text { Psychiatry } & 1243-1251 .\end{array}$ https://doi.org/10.1001/jamapsychiatry.2015.2196

Rauch, S.L., Shin, L.M., Dougherty, D.D., Alpert, N.M., Fischman, A.J., Jenike, M.A., 2002. Predictors of fluvoxamine response in contamination-related obsessive compulsive disorder: a PET symptom provocation study. Neuropsychopharmacol. Off. Publ. Am. Coll. Neuropsychopharmacol. 27, 782-791. https://doi.org/10.1016/S0893-133X(02)00351-2

Reckless, G.E., Andreassen, O.A., Server, A., Østefjells, T., Jensen, J., 2015. Negative symptoms in schizophrenia are associated with aberrant striato-cortical connectivity in a rewarded perceptual decision-making task. Neurolmage Clin. 8, 290-297. https://doi.org/10.1016/j.nicl.2015.04.025

Richter, A., Petrovic, A., Diekhof, E.K., Trost, S., Wolter, S., Gruber, O., 2015. Hyperresponsivity and impaired prefrontal control of the mesolimbic reward system in schizophrenia. J. Psychiatr. Res. 71, 8-15. https://doi.org/10.1016/j.jpsychires.2015.09.005

Schlagenhauf, F., Huys, Q.J.M., Deserno, L., Rapp, M.A., Beck, A., Heinze, H.-J., Dolan, R., Heinz, A., 2014. Striatal dysfunction during reversal learning in unmedicated schizophrenia patients. Neurolmage 89, 171-180. https://doi.org/10.1016/j.neuroimage.2013.11.034

Schlagenhauf, F., Sterzer, P., Schmack, K., Ballmaier, M., Rapp, M., Wrase, J., Juckel, G., Gallinat, J., Heinz, A., 2009. Reward feedback alterations in unmedicated schizophrenia patients: relevance for delusions. Biol. Psychiatry 65, 1032-1039. https://doi.org/10.1016/j.biopsych.2008.12.016

Schlosser, D.A., Fisher, M., Gard, D., Fulford, D., Loewy, R.L., Vinogradov, S., 2014. Motivational deficits in individuals at-risk for psychosis and across the course of schizophrenia. 
Schizophr. Res. 158, 52-57. https://doi.org/10.1016/j.schres.2014.06.024

Schultz, W., 2001. Reward signaling by dopamine neurons. Neurosci. Rev. J. Bringing Neurobiol. Neurol. Psychiatry 7, 293-302. https://doi.org/10.1177/107385840100700406

Simon, J.J., Biller, A., Walther, S., Roesch-Ely, D., Stippich, C., Weisbrod, M., Kaiser, S., 2010. Neural correlates of reward processing in schizophrenia--relationship to apathy and depression. Schizophr. Res. 118, 154-161. https://doi.org/10.1016/j.schres.2009.11.007

Smieskova, R., Roiser, J.P., Chaddock, C.A., Schmidt, A., Harrisberger, F., Bendfeldt, K., Simon, A., Walter, A., Fusar-Poli, P., McGuire, P.K., Lang, U.E., Riecher-Rössler, A., Borgwardt, S., 2015. Modulation of motivational salience processing during the early stages of psychosis. Schizophr. Res. 166, 17-23. https://doi.org/10.1016/j.schres.2015.04.036

Subramaniam, K., Hooker, C.I., Biagianti, B., Fisher, M., Nagarajan, S., Vinogradov, S., 2015. Neural signal during immediate reward anticipation in schizophrenia: Relationship to realworld motivation and function. Neurolmage Clin. 9, 153-163. https://doi.org/10.1016/j.nicl.2015.08.001

Thorsen, A.L., Hagland, P., Radua, J., Mataix-Cols, D., Kvale, G., Hansen, B., van den Heuvel, O.A., 2018. Emotional Processing in Obsessive-Compulsive Disorder: A Systematic Review and Meta-analysis of 25 Functional Neuroimaging Studies. Biol. Psychiatry Cogn. Neurosci. Neuroimaging 3, 563-571. https://doi.org/10.1016/j.bpsc.2018.01.009

van Erp, T.G.M., Preda, A., Nguyen, D., Faziola, L., Turner, J., Bustillo, J., Belger, A., Lim, K.O., McEwen, S., Voyvodic, J., Mathalon, D.H., Ford, J., Potkin, S.G., Fbirn, null, 2014. Converting positive and negative symptom scores between PANSS and SAPS/SANS. Schizophr. Res. 152, 289-294. https://doi.org/10.1016/j.schres.2013.11.013

Walter, H., Kammerer, H., Frasch, K., Spitzer, M., Abler, B., 2009. Altered reward functions in patients on atypical antipsychotic medication in line with the revised dopamine hypothesis of schizophrenia. Psychopharmacology (Berl.) 206, 121-132. https://doi.org/10.1007/s00213009-1586-4

Wilson, R.P., Colizzi, M., Bossong, M.G., Allen, P., Kempton, M., MTAC, Bhattacharyya, S., 2018. The Neural Substrate of Reward Anticipation in Health: A Meta-Analysis of fMRI Findings in the Monetary Incentive Delay Task. Neuropsychol. Rev. https://doi.org/10.1007/s11065018-9385-5

Winton-Brown, T.T., Fusar-Poli, P., Ungless, M.A., Howes, O.D., 2014. Dopaminergic basis of salience dysregulation in psychosis. Trends Neurosci. 37, 85-94. https://doi.org/10.1016/j.tins.2013.11.003

Zhang, B., Lin, P., Shi, H., Öngür, D., Auerbach, R.P., Wang, Xiaosheng, Yao, S., Wang, Xiang, 2016. Mapping anhedonia-specific dysfunction in a transdiagnostic approach: an ALE metaanalysis. Brain Imaging Behav. 10, 920-939. https://doi.org/10.1007/s11682-015-9457-6 